\title{
A SERVICE INFRASTRUCTURE TO SUPPORT UBIQUITOUS ENGINEERING PRACTICES
}

\author{
Yacine Rezgui and Benachir Medjdoub \\ Informatics Research Institute, University of Salford, Salford, UK. \\ School of Architecture, University of Nottingham, , Nottingham, UK \\ y.rezgui@salford.ac.uk; B.Medjdoub@nottingham.ac.uk
}

\begin{abstract}
Ubiquitous computing allow's users to move between gateways to the information world in ways that are appropriate to their current physical as well as contextual settings. Advanced visualization techniques, including immersive displays and augmented reality, have the potential to address the collocation needs of mobile engineering teams, and enhance their collaboration effectively. The paper explores the use of innovative technologies for implementing a ubiquitous engineering service infrastructure. This comprises a wide range of value-added engineering services that make use of visualization technologies - combined with location tracking techniques - to convey user and context sensitive, semantically enriched, high dimensional multimedia contents.
\end{abstract}

\section{INTRODUCTION}

The convergence of ubiquitous computing and visualization technologies is creating unprecedented opportunities for engineering teams to respond more effectively to the increasing demand for sophisticated, customized, and high quality products and services in industry. Ubiquitous computing allows people to move between gateways to the information world in ways that are appropriate to their current physical as well as contextual settings. Visualization related technologies, from immersive displays to Augmented Reality (AR), are today routinely used in industry, with huge potential in engineering, health, heritage and archaeology $[1,2]$.

Construction is one of the sectors with strong potentials to benefit from these advanced technologies. Over the last few decades it has become increasingly heterogeneous and highly fragmented, depending upon a large number of very different professions ranging from design and engineering firms to component/ product manufacturers, with ever-growing pressures from clients (building owners) to deliver sophisticated facilities on time and on budget. Within the framework of geographical dispersion, the construction industry is characterized by various challenges in terms of working practices $[8,9,10]$, including: (a) non co-location of individuals and teams collaborating on projects; (b) the project-oriented nature of the industry, with a tendency for actors to be involved in several projects simultaneously; (c) multi-disciplinary and mobile-working practices; (d) the temporary and often short-term nature of business relationships. In this context, new and novel communication and visualization technologies have the potential to radically change the process of building design and construction, and match more closely the formal aspirations of modern design and engineering teams. 
The present research explores the use of innovative technologies for implementing a ubiquitous engineering service infrastructure. This comprises a wide range of value-added engineering services that make use of visualization technologies - combined with location tracking techniques - to convey user and context sensitive, semantically enriched, high dimensional multimedia contents. This is achieved through a variety of display devices ranging from traditional desktop monitors to head mounted display and wearable devices with real time augmented reality capabilities.

\section{CURRENT ENGINEERING PRACTICES}

Current engineering practices in Construction are diverse and very much influenced by existing information and communication technologies (ICT). Hardware and software infrastructures used to support communication and collaboration within organizations and across projects are most of the time owned or, in some very few instances, leased. Given the dominant SME nature of Construction [8], there is a strong reluctance to invest in ICT infrastructures due to financial considerations. The prevailing model for software provision is licensing. However, the licensed software is rarely exploited to its full potential, as users tend to use a limited range of the available functionality. This, in fact, creates a perception of complexity and can act as a barrier to software adoption.

Software applications often require ad-hoc integration to enable seamless collaboration between individuals and teams on projects. This is however repeated on each project, as partners tend to bring and use their own software [11]. Data and information redundancy are real issues, as information tends to be owned and managed across individuals, teams, and projects with no particular agreed policy. This leads to severe information inconsistency and regulatory compliance problems, resulting in dramatic financial implications.

Practitioners tend to be tied to a physical location (mainly their office) to do their jobs. Software is accessed through desktops and, in very few instances, through laptops on site. Support and maintenance is provided through many points of service representing the different technology licensees.

\section{RELATED TECHNICAL AREAS}

Several research areas underpin the vision of ubiquitous computing. Three particular ones are relevant for the present research, namely: Service-oriented computing, Location tracking, and Augmented reality.

Service-Oriented Computing (SOC) is becoming the prominent paradigm for leveraging inter and intra enterprise information systems. Web-services have attracted enormous interest from the research community and industry in recent years and have emerged as a serious candidate for deploying service-oriented solutions [10]. Web services are self-contained, web-enabled applications capable not only of performing business activities on their own, but also possessing the ability to engage other web services in order to complete higher-order business transactions [20]. The benefits of web services include the decoupling of service interfaces from implementation and platform considerations, the support for dynamic service binding, and an increase in cross-language and cross-platform interoperability. The challenge of this new form of computing is to move from its 
initial "Describe, Publish, Interact" capability to support dynamic composition of services into reinvented assemblies, in ways that previously could not be predicted in advance [17].

In terms of location tracking, devices that track in three dimensions the position and orientation of wearable displays, including Head Mounted Displays (HMD), are used to render 3D virtual objects aligned with the physical world. There are a number of different tracking technologies used, varying by the number of dimensions measured and the physical properties used [19]. Relevant technologies include Real-time Kinematic (RTK) GPS, ground-based pseudo-satellite (or pseudolite) technology, and Inertial Navigation System (INS).

Natural interfaces offered by devices such as walk-in displays, body tracking, and haptics allow non co-located people to interact with each other in a natural way. More realistic and faithful models can be visualized thanks to improvements in data capture and display technologies (ranging from digital projectors and plasma screens to wearable devices) and the availability of computing power (offered by commodity graphics cards and GRID technology) capable of rendering such data in real time [13]. On the other hand, Augmented Reality (AR) augments real world experiences by adding computer-generated experiences. AR addresses two major issues with collaboration: (a) seamless integration with existing tools and practices; and (b) enhancing practice by supporting remote and collocated activities that would otherwise be impossible. AR research has developed rapidly over the last decade [1].

\section{E-SERVICES IN CONSTRUCTION}

Over the last few years, traditional e-commerce is giving way to a new paradigm known as "e-service". E-services include all interactive services that are delivered on the Internet using advanced telecommunications, information, and multimedia technologies [14]. This emerging paradigm represents a coherent point of view that challenges many of the traditional assumptions about how to use the online environment to raise profits (Rust and Lemon, 2001). It is based less on reducing costs through automation and increased efficiency and more on expanding revenues through enhancing service and building profitable customer relationships [15, 16].

As argued by several authors [18], e-services can be classified according to two dimensions: their origin and nature / type of goods supplied (Table 1). The first dimension relates to how well an e-service provider is rooted in the physical world. E-service providers having their origins as a dot.com can be thus distinguished from those having traditional roots. For the latter, the portal site itself is an extension, whereas dot.com starters have always operated in the e-world, while the portal is the original brand. The second dimension concerns the type of products that are supplied. Some e-service providers supply tangible goods or traditional services: the websites mainly function as a distribution channel, an on-line store or an interface with customers. In contrast, other e-service providers offer virtual products, remaining within the borders of the e-world: search functions, communication tools, information, downloadable software etc. Based on the framework depicted in Table 1 , there are several variants of the e-Services models in Construction characterized by their intended use. These are categorized below. 
Table 1- Classification of e-Services in Construction.

\begin{tabular}{|c|c|c|c|}
\hline $\begin{array}{l}\text { e-Services in } \\
\text { Constructio } \\
\text { n }\end{array}$ & \multicolumn{3}{|c|}{ Origin } \\
\hline \multirow{6}{*}{ Product } & & Virtual & Physical \\
\hline & \multirow{3}{*}{ Virtual } & \multirow[t]{2}{*}{$\begin{array}{l}\text { Specialised Portals aiding at } \\
\text { selecting the right products } \\
\text { taking into account cost, quality } \\
\text { and performance parameters }\end{array}$} & $\begin{array}{l}\text { Software manufacturers } \\
\text { that have developed } \\
\text { service-based } \\
\text { of their solutions } \\
\text { products. }\end{array}$ \\
\hline & & & $\begin{array}{l}\text { Access to Construction } \\
\text { regulations online. }\end{array}$ \\
\hline & & $\begin{array}{l}\text { Access to semantic resources in } \\
\text { the Construction domain: } \\
\text { thesauri, dictionaries, etc. }\end{array}$ & $\begin{array}{l}\text { Access to construction } \\
\text { organization details and } \\
\text { yellow pages. }\end{array}$ \\
\hline & \multirow{2}{*}{ Physical } & \multirow{2}{*}{$\begin{array}{l}\text { Virtual team work and } \\
\text { enterprise solutions, e.g. } \\
\text { Buildonline, Bricsnet, Buzzsaw, } \\
\text { Citadon. }\end{array}$} & $\begin{array}{l}\text { Product / equipment } \\
\text { Manufacturers and } \\
\text { suppliers. }\end{array}$ \\
\hline & & & $\begin{array}{l}\text { Selling Construction } \\
\text { Products on line }\end{array}$ \\
\hline
\end{tabular}

\section{1 e-Services as Enhanced Customer-driven e-Commerce}

This is where traditional e-commerce approaches that tended to focus on automating "product selling" practices have been extended to provide a service dimension to the customer using Customer Relationship Management (CRM) techniques. Moreover, there is a difference between conducting basic e-commerce purchases and adopting e-services. In comparison to one-time e-commerce-based purchases, the e-service adoption decision is typically more complex, as it initiates a long-term relationship between the consumer and service provider [4]. E-services can take the form of Consumer and Trading Portals providing advanced market-maker e-services such as reverse auctions and collective bidding. A great deal of services in the Construction sector falling under this category has emerged over the last few years. These are developed mainly in the area of product manufacturers and suppliers.

\section{2 e-Services as a new software-licensing paradigm}

Increasing complex business processes require the use of a variety of software packages but only a few packages are used on a daily basis. This infrequent usage pattern often does not justify purchasing full licenses and therefore motivates a need for more flexible way to use and pay for usage of software [5]. Although, in the late 1990s, a host of start-ups began offering applications delivered over the Web using a pay-per-use cost model, most of them went out of business, mainly because large corporate customers balked at the idea of allowing untested outsiders to run their 
most important applications. But in the past couple of years, both corporations and smaller businesses have become more comfortable with this way of buying software [3]. Many software publishers are today reconsidering their software distribution methods. They deliver application software and services (software maintenance, upgrades, staff training, etc.) over the Web on a lease or subscription basis instead of the traditional perpetual licensing model [11]. Several leading software vendors have started adopting this new business model emphasizing cost savings factors. Analysts now estimate that over the next half-decade, as much as half the software sold to corporations will be paid for on a monthly basis, as part of a long-term contract or a monthly rental fee, or even on a pay-per-use basis [3].

This new form of software licensing provides a software service that includes configuration, maintenance, training and access to a help-desk. It enables organizations to rent as opposed to purchase software. This involves using only the functionality directly needed by the user, therefore reducing cost and increasing work efficiency. In the Construction sector, such services include solutions from Bricsnet (http://www.bricsnet.com), Buzzsaw (http://www.buzzsaw.com), BuildOnline (http://www.build-online.com) and Citadon (http://www.citadon.com).

\section{3 e-Services as a mean to enable e-Processes}

Businesses now have a new opportunity to rethink fundamental aspects of Information Technology (IT). One of the key capabilities within e-services can also be applied to elements of a business' IT infrastructure to facilitate the execution of distributed business processes implemented through a coordinated composition and invocation of web-enabled, service-oriented, corporate Enterprise Information Systems applications. For example, messaging/email can now be provided to the employees of an enterprise using a service-based approach. This frees time and money for the IT organization to invest elsewhere - into areas that can better serve their customers and their partners. The e-services model has been used by some leading organizations to better integrate their in-house legacy as well as commercial software applications, thus becoming ubiquitous and providing better support to mobile users. Some leading construction organizations have started investigating and investing into these technologies [10].

\section{CONCEPTUALISATION OF THE UBIQUITOUS ENGINEERING SOLUTION}

The underlying conceptualization of the solution is influenced by BPEL4WS as illustrated in Figure 1. A Construction project operates as a Virtual Enterprise [10]. This is assigned a dedicated Workspace environment. In order to reflect the discipline-oriented nature of the sector, a Workspace can involve other Workspaces in a recursive manner. Business processes interact, on a peer-to-peer basis, with a set of Services by invoking one or several of the Methods they support. Methods represent API calls, or functionality, of such services. The way messages are exchanged between the business process and the Service Methods is described through the concept of Activity. The proposed model supports the allocation of such services to Virtual Enterprises and Workspaces within them. Access to Services and Methods from within an individual project is controlled through WorkspaceRoles. 
An Actor must hold at least one WorkspaceRole, which corresponds to an actual role that is held within a project. This is vital because, whilst it allows the system to capture some semantics about members having performed a task through the WorkspaceRole.

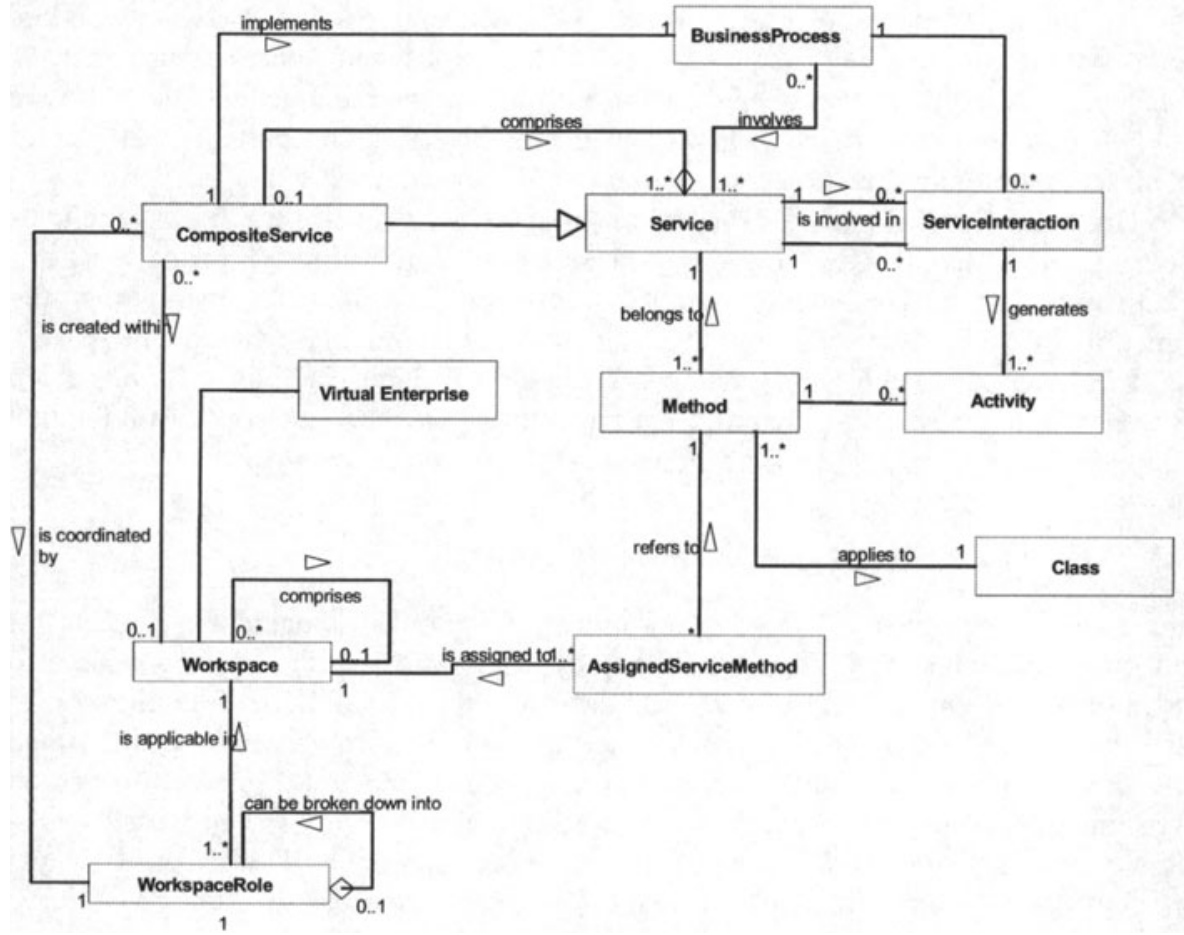

Figure 1- Conceptualization of the solution.

The proposed architecture (Figure 2) makes use of established work, initiatives and standards in the web services domain (including BPEL4WS, WS-Security, WS-Coordination, WS-Transaction). Each layer represents the main building blocks supporting the ubiquitous engineering vision. The service manager box provides access to the API functions necessary for all aspects of invocation, registration and de-registration of services (including web-serviced end-user legacy and commercial design \& engineering applications), as well as their publication in a dedicated UDDI registry. The Business Process Specification Layer (BPSL) includes the API functions that enable service composition in order to implement a given business process as described in the previous section. Specialized services are specified in the following layer, including augmented Reality, location tracking, Multi-modal presentation, and user profiling. The business process composition relies on a set of core services concerned with service coordination, transaction, and security. The lower part of the picture represents all web-serviced applications that are ready for invocation and use as part of a service composition exercise in order to implement a business process. 


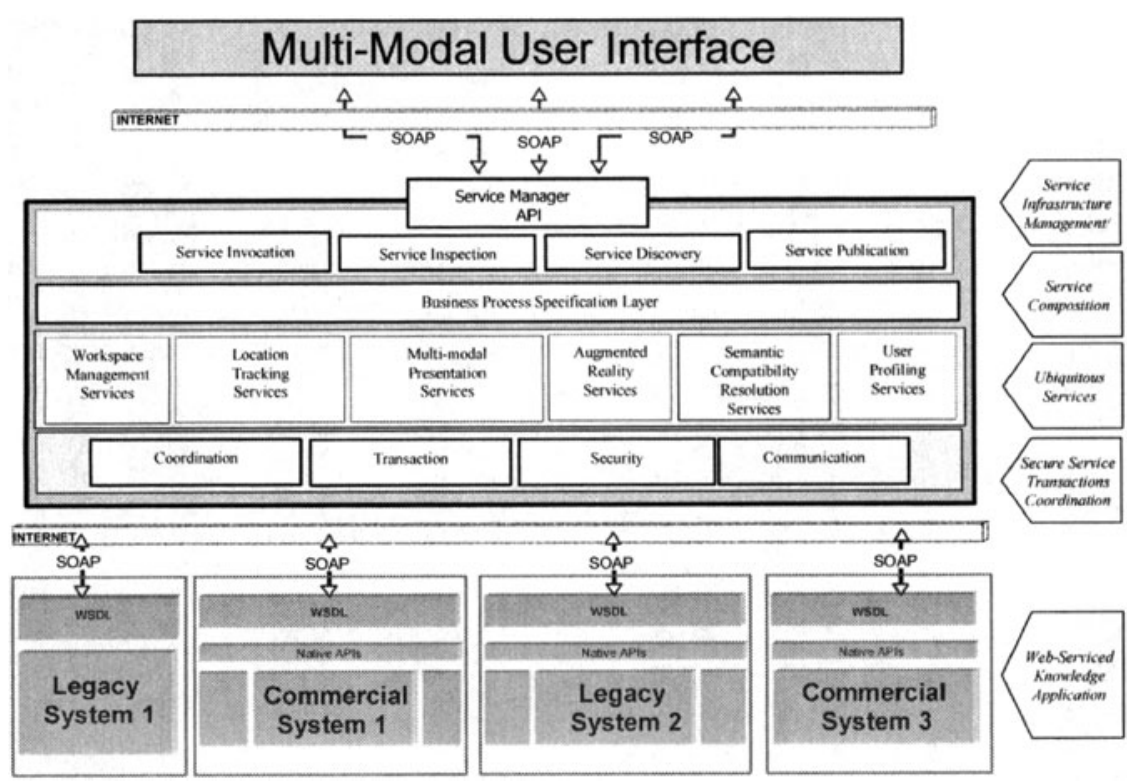

Figure 2 - Architecture of the ubiquitous service infrastructure.

\section{CASE STUDIES}

To illustrate the main concept described in this paper, two applications (outdoor and indoor augmented reality systems) are presented. These are described below.

\subsection{A mobile system for an outdoor augmented visualisation in architecture}

Architects design buildings in their offices using a variety of drawings ranging from plans to $3 \mathrm{D}$ perspectives. In the best scenario, an architect would use CAD (Computer-Aided Design) software to visualize the building in $2 \mathrm{D}$ or $3 \mathrm{D}$, and then superimpose an image of the virtual building on an image of the real site to evaluate his/her design. For any modification, the architect has to (a) go back to the building $3 \mathrm{D}$ model, (b) do the necessary modification(s), and (c) produce the image again where the virtual building is superimposed on the real site. In the proposed approach, an on-site real-time augmented visualization system is used to assist architects to visualize/modify/evaluate their design in real time. A dedicated set of functionalities delivered in the form of web-services is invoked through a PDA to manipulate/modify the 3D virtual model of the building. Location tracking techniques (GPS and INS) are used via a see-through head mounted display to visualize the real site (including the existing building) augmented with the virtual 
extension. The existing site is illustrated in Figure 3al. The designer invokes a service, Add_Building_Element (), to add an overhanging structure to the existing building. This service, in turn, invokes the methods Superimpose_Models () and Render_Design () to deliver the resulting augmented reality design on the designer's head mounted display (Figure 3a2). While assessing the extension, the added building element has triggered automatically, through a service composition procedure, the method Dimension_Model (). The latter identifies a critical structural weakness, due to the length of the overhanging structure, and suggests the addition of two columns to improve the resistance and stability of the overall building (Figure 3a3). Once validated, the Approve_Design () service is invoked, aimed at the lead architect back in the designer's office.

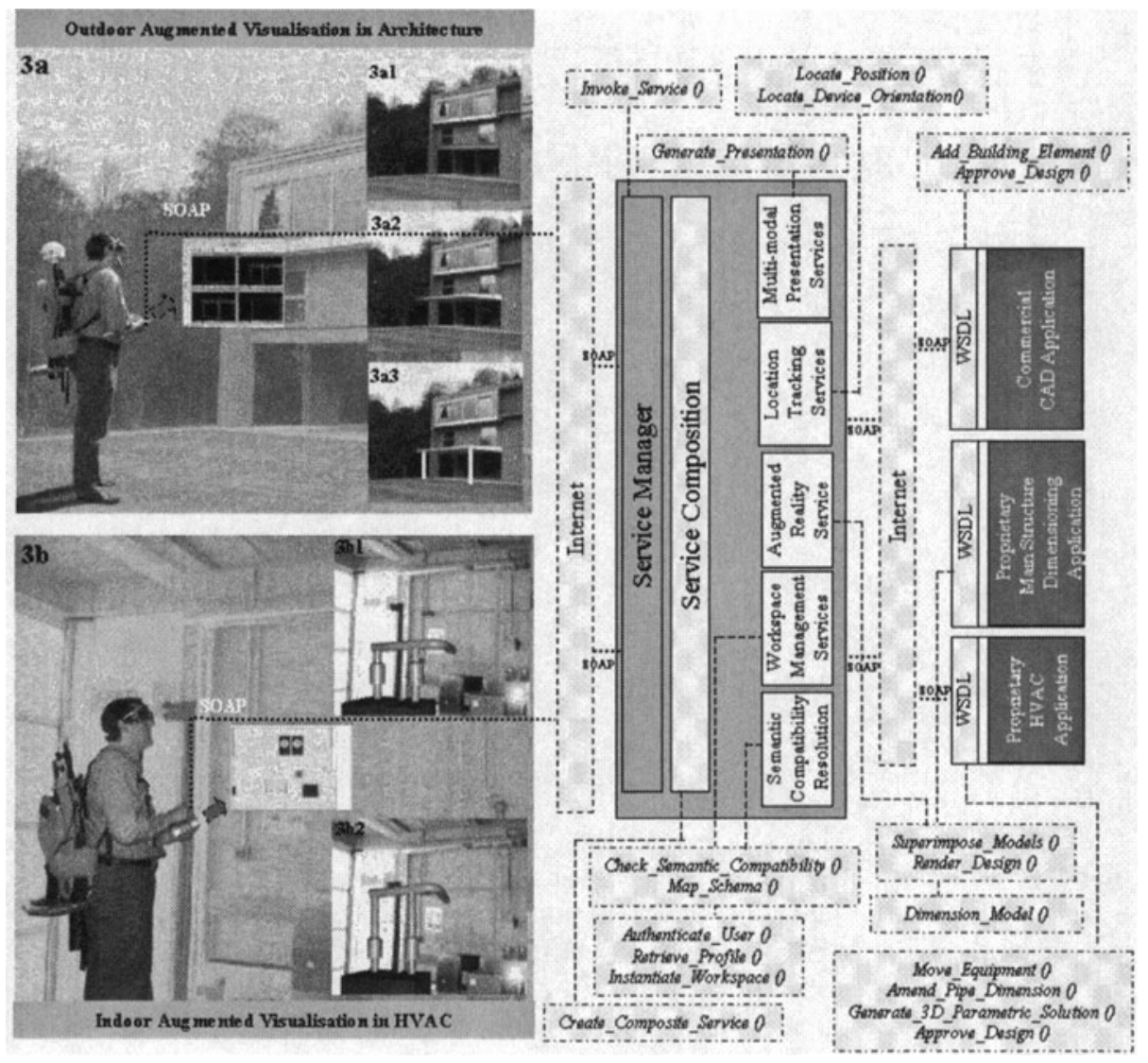

Figure 3 - Ubiquitous access to services in Practice.

\subsection{A mobile system for an indoor augmented reality in building services}

Currently, the design of heating and ventilation plants is done at work using CAD and simulation software. Thus, starting from the heating load in $\mathrm{kW}$, the building service engineer defines two-dimensional schematic solutions consisting of a set of plans of the building including the equipment location (e.g. boilers, pumps, etc.) and the pipe routing. Through the design process, the engineer has no possibility to 
check the design on site (plant room space augmented with the virtual 3D solution) and to make the necessary modification(s) if applicable (e.g. an error in the height of the flue pipes). For any design modification, the engineer has to go back to the office and modify the design accordingly.

Through the proposed system, the engineer has the possibility to generate $3 \mathrm{D}$ plant room solutions and visualize them on site. A dedicated set of functionality delivered in the form of web-services is invoked through a PDA to generate 3D plant room solutions, including equipment location and pipe routes [6,7]. Motion tracking sensors and a see-through Head mounted display are used to visualize the real site augmented with the virtual $3 \mathrm{D}$ solution.

The service-based solution proceeds in the following way. The HVAC engineer invokes a dedicated web-service that generates an optimised 3D parametric solution using Constraint Logic Programming. The service, Generate_3D_Parametric_Solution (), takes the plant room geometry and the heating load in $\mathrm{k} \overline{\mathrm{W}}$ as input. First, the standard number and size of modular boilers, pumps, etc., are determined from the heat load. Then, a compatible optimising 3D parametric solution is generated. The novelty of the approach is that it is highly interactive. Modifying the topology of the generated solution is done directly through the graphic interface of the PDA. For example, modifying the position of a boiler is done in two steps. First, the engineer invokes the method Move_Equipment () to specify the new physical location of the boiler. This can also be achieved by a simple dragging routine. The CAD system automatically updates the 3D model including the pipe-routing, while maintaining all the constraints, hence the validity of the design. Once the modification is made, the engineer invokes another web service, Approve_Design (), which is submitted to the lead engineer for approval. Only once this is granted can the amendment be made effective.

The scenario illustrated in Figure $3 \mathrm{~b}$ illustrates an engineer on site invoking a service via SOAP to visualise a plant room solution on his head mounted display (Figure 3b1: 2 Boilers and flue pipes) obtained through Generate_3D_Parametric Solution () web service. Figure $3 \mathrm{~b} 3$ illustrates the HVAC application platform graphic interface. Next, the engineer invokes another service, Amend_Pipe_Dimension (), to change the height of the flue pipe and visualise the new solution on his HMD in real time (Figure 3b2).

\section{CONCLUSION}

The research and evaluation of the deployment work has identified (a) a need to have flexible and reusable composite services, and (b) mechanisms to support smart composition of web services to implement a given business process. In fact, web service composition, even when developed using BPEL is not adaptive to change. If the requirements of the application change or need extending, the service composition needs to be re-specified from scratch. It is currently not possible to define and implement a web service composition once and use it in similar designs with some variations in a later stage. A more flexible approach allowing service reuse, extension, and specialization should be supported in a way that is similar to component-based development. Some work has already been done in this area [11]. In relation to aspect (b), web service composition methodologies have a focus on syntactic integration and therefore do not support automatic composition of web services. As highlighted in [12], semantic integration becomes crucial for web 
services as it allows them to: (a) represent and reason about the task that a web service performs; (b) understand the meaning of exchanged messages; (c) represent and reason about preconditions that are required to use the service and the effects of having invoked the service; and (d) allow intelligent composition of web services to achieve a more complex service. These constitute the current challenges and future directions for research tackled by the authors and the web services community.

\section{REFERENCES}

[1] Azuma, R.T., Y. Baillot, R. Behringer, S. Feiner, S. Julier, and B. MacIntyre, 2001, "Recent Advances in Augmented Reality", IEEE Computer Graphics and Applications, 21 (6). pp. 34-47.

[2] Burdea, G.C. and Coiet, P.: Virtual Reality Technology. Wiley-Interscience (2003).

[3] Business Week (2004), "Pay-As-You-Go is Up and Running," Business Week, January 12, pp. 93-94.

[4] Featherman, M.S., and Pavlou P.A. Predicting E-services Adoption: A Perceived Risk Facets Perspective, International Journal of Human-Computer Studies, 59, pp. 451-474, 2003.

[5] Fenicle, B., and Wahls, T. A Methodology to Provide and use Interchangeable Services, SAC 2003, Melbourne, Florida, USA, 2003.

[6] Medjdoub, B., Richens, P. and Barnard, B. Generation of Variational Standard Plant Room Solutions, Automation in Construction Journal, 12(2), pp. 155-166, 2003.

[7] Medjdoub, B. and Yannou, B. "Dynamic space ordering at a topological level in space planning", Artificial Intelligence in Engineering, 15(1), pp. 47-60, 2001.

[8] Rezgui, Y. Review of Information and Knowledge Management Practices State of the Art in the Construction Industry, Knowledge Engineering Review, Issue 16(3), pp. 241-254, 2001.

[9] Rezgui, Y., Zarli, A. Paving the way to digital construction: a strategic roadmap, Journal of Construction Management and Engineering (Journal of the American Society of Civil Engineering), 132(7), pp. 767-776, 2006.

[10] Rezgui, Y. Role-Based Service-Oriented Implementation of a Virtual Enterprise: A Case Study in the Construction Sector, Computers in Industry (Elsevier), 58(1), pp. 74-86, 2007.

[11] Rezgui, Y. Exploring Virtual Team-Working Effectiveness in the Construction Sector, Interacting with Computers (Elsevier), 19(2), pp. 96-112, 2007.

[12] Rezgui, Y. and Nefti-Meziani, S. Ontology-Based Dynamic Composition of Services Using Semantic Relatedness and Categorisation Techniques, ICEIS: 9th International Conference on Enterprise Information Systems, 12-16, June 2007, Funchal, Madeira - Portugal.

[13] Roberts, D., Wolff, R. and O. Otto, "Constructing a Gazebo: Supporting teamwork in a tightly coupled, distributed task in virtual reality," Presence: Teleoperators \& Virtual Environments, vol. $12,2003$.

[14] Roth, A.V. Service Strategy and the Technological Revolution, In J.A.D. Machuca, T. Mandakovic (Eds.), POM Facing the New Millennium: Evaluating the Past, Leading With the Present and Planning the Future of Operations, Production and Operations Management Society and the University of Sevilla, Sevilla, 2000, pp. 159-168, 2000.

[15] Rust, R., and Kannan, P.K. E-Service: A New Paradigm for Business in the Electronic Environment, Communications of the ACM, 46(6), 2003.

[16] Ruyter, K.de, Wetzels, M., Kleijnen, M. Customer Adoption of E-Service: An Experimental Study, International Journal of Service Industry Management 12 (2), pp. 184-206, 2001.

[17] Van Den Heuvel, W.J., Maamar, Z. Moving Towards a Framework to Compose Intelligent Web Services, Communications of the ACM, vol. 46, no. 10, Oct 2003, pp. 103-109.

[18] Van Riel, A.C.R., and Ouwersloot, H. Extending Electronic Portals with New Services: Exploring the Usefulness of Brand Extension Models, Journal of Retailing and Consumer Services, 12 (3), pp. 245-254, 2005.

[19] Welch, G. and Foxlin, E. Motion Tracking: No Silver Bullet, but a Respectable Arsenal. IEEE Computer Graphics and Applications, Vol. 22, No. 6, pp. 24-38, 2002.

[20] Yang, J. Web Service Componentization," Communications of the ACM, vol. 46, no. 10, Oct 2003, pp. 35-40. 